\title{
Medical Simulation a Tool yet Untapped in Most Developing Nations in Africa
}

\author{
Olalere.A.Abass \\ Dept. of Computer Science \\ Tai Solarin College of \\ Education
}

\author{
Babafemi.O.Samuel \\ Dept. of Computer Science \\ Tai Solarin College of \\ Education
}

\author{
Gabriel.T.Odufeko \\ Dept. of Biology \\ Tai Solarin College of \\ Education
}

\begin{abstract}
Delicate surgeries and acute medical cases in Africa are often referred to the developed countries of the world with sophisticated medical services. One marvels at the millions of cash which covers cost of travelling and treatment invested to save a life, while the developed countries continues to thrive ahead in doing the needful in fostering their healthcare services, Africa has been left behind.

The role of medical simulation in ensuring improvement in medical practices in the developed nations of the world can't be underestimated. It is a "phenomenon" flourishing and as such developing nations in Africa should tap into its limitless opportunities in bringing advancement to its healthcare system. This paper intends to elucidate the benefits of medical simulation and justify reasons why the African continent should embrace it.
\end{abstract}

\section{General Terms}

Simulation, Medical Simulation.

\section{Keywords}

Simulation in Healthcare, Clinical Simulation, Health Practitioner Efficiency, Benefits of Medical Simulation.

\section{INTRODUCTION}

The imitation of a real-world process or operation of a system over time is called simulation [1]. It encompasses the development of a model that will replicate the key features and attributes of an actual system. The model represents the system itself, while simulation represents the behaviour of the system over time.

With the aid of a scientific model, simulation can be used to gain insight into the functioning of human and natural systems ([2], [4]). It is also used to determine the exact effect of different courses of actions taken on a particular system. Simulation is also applicable when the real system cannot be engaged because it may be risky and dangerous, could be under construction or simply may not exist. ([3], [4]). Many cutting edge advancement in various fields ranging from medicine, manufacturing, aviation, driving, transportation, automobiles, urban planning, military etc. have been created through the use of simulation.

The focus of this paper is to dwell extensively on the application of simulation to medicine and healthcare system which in general term is often referred to as "medical simulation". Medical simulation is a relatively new concept for training and evaluation of physicians in healthcare, it includes diverse range of techniques from role-playing actors, differential diagnosis clinical scenarios to cadaveric dissection and stored "classic disease" imaging studies which have been used to educate generations of physicians [5].

This work will also justify why this technique should be embraced in ensuring the best medical practices in developing countries in Africa.

\section{MEDICAL SIMULATION AT A GLANCE}

The first incidence of medical simulation was by Dr Gregoire of Paris in the $17^{\text {th }}$ century where he used a manikin he created to demonstrate a stretched skin over a pelvis to imitate attributes of an abdomen through the use of a dead foetus to explain assisted and complicated deliveries to midwives [14]. These models evolved and developed with time, today it is being used as a diagnostic tool to demonstrate the clinical features of certain diseases.

The first major step taken in creating simulators that will model functions of human body was achieved by the University of Miami in USA through the creation of its famous Harvey mannequin that recreated the key characteristics of a cardiology examination including palpation, auscultation and electrocardiography. Elsewhere in Europe, different companies were springing up developing technologies that will aid physicians in managing the reaction of human body to trauma. Several simulators such as resuscitation training mannequins, portable ventilation and airway control machines were developed in order to provide efficient on-scene emergency treatment, proper and adequate ventilation control in order to manage the needs of patients during cardiac arrest.

The national institute of health virtual human project in 1986 in USA created the platform to use simulation as a training tool with its invention of a complete, anatomically correct, three-dimensional representation of both the male and female human bodies; this was complemented with transverse CT, MR and cryo-section images. The end result of this project will be a library that links visual images and data to the names of body parts, providing the medical reference on the human body's reaction to a variety of stimuli.

Between the mid to late 90's, companies such as Laerdal, Medical Education Technologies (METI), Mentice, and Simbionix, to mention a few springed up and developed sophisticated medical simulators which was being used to train healthcare professionals [6] .

At presence medical simulators are increasingly being developed and deployed to teach therapeutic and diagnostic 
procedures as well as medical concepts and decision making to personnel in the health profession. Simulators have been developed for training procedures ranging from the basics such as blood draw to laparoscopic surgery [7] and trauma care. They are also important to help on prototyping new devices [8] for biomedical engineering problems. Currently, simulators are applied to research and develop tools for new therapies, [9] treatments [10] and early diagnosis [11] in medicine.

Recently David Gaba [12] structured the models used in medical simulation into five categories. These 5 designations are verbal, standardized patients (SP's), part task trainers, computer patient, and electronic patient. Verbal simulation is a form of human simulation which basically involves role playing. Standardized patients are often actors who are used to educate and examine physical examination skills. Part-task trainers range from static models and audio-visual devices to the more complex modern surgical task trainer. It is sophisticated and computer driven. Task trainers could either be low fidelity or high fidelity. Computer patients are interactive and software inclined. Computer patients are virtual while standardized patients are real but the former serves the same functions like SP's at a reduced cost. The most comprehensive form of simulation is the electronic patient. Electronic patients can be either mannequin or VRbased and replication of the clinical environment is integral. [13]

\section{SIMULATION IN HEALTHCARE}

The urge to reduce risk and cost, create an avenue to demonstrate, examine and evaluate a wide range of skills, test run new techniques has led to the explosive growth and advancement of simulation in medicine [14]. Simulation in healthcare is broad and has diverse potentials thus it can be classified into major directions. Each major classification can be further divided into sub-disciplines. Below is the major classification of healthcare simulation:

- Clinical Simulation: It involves the studying, analysis and reproduction of features of certain diseases which may include biological processes in the body system of human.

- Operational Simulation: It is mainly used for capturing, analysing, studying healthcare operations, service delivery, scheduling, healthcare business processes and patient flow.

- Managerial Simulation: This type of simulation involves planning, coordinating, management, evaluating healthcare operations, policy implementation and decision taking for effective service delivery.

- Educational Simulation: It is basically used for teaching, training and educational purposes. Educational simulation is virtual and can be used as a substitute when it is deemed fit that the actual environment may not exist or it may be risky and costly.

The above classification only suggests the vast scope of simulation applicability in relation to the healthcare domain. In each of the above directions, simulation can be used for analysis and design, learning and training, research and communication purposes.

\subsection{Benefits of Medical Simulation}

The increasing importance of simulation in healthcare services is not an understatement but a tool which as at today is fast becoming a platform for training medical practitioners in achieving the best medical performance possible. Below are some of the reasons why simulation is gradually becoming of widespread use in medicine.

- Health practitioner efficiency - Patients forms the nucleus of every healthcare system. This implies that adequate attention must be dedicated to safety and treatment of patients by experienced personnel. A poor health system is an indication of inexperienced medical staff coupled with lack lustre health facilities. It is an ethical obligation to ensure that medical professionals are exposed to different clinical challenges to get them prepared prior to encountering real-life challenges. The use of medical simulation allows health practitioners to realise that patients are not training tools but "precious gift" whose safety should be paramount and jealously guided.

- Less prone errors - Errors have become a part of human existence but more grievous is if errors are made and not corrected or allow to be repetitive. Simulation allows clinicians in training to take risks, to further experiment in procedures which normally would not be allowed in real patients and to make errors without penalty. Since such mistakes made during simulated exercises do not jeopardize patient safety, physicians can reviewed and rectify it without feelings of blame and guilt thus leading to perfection (lesser error) thereby achieving the utmost goal "patient safety".

- Breaking barriers - Simulation in medicine is like a microscope shedding more light into new research areas which may be complex in the real world. It allows medics to break barriers by wanting to know more hence creating a health care system thriving towards efficiency.

- Teacher-enabled environment - The tradition of waiting for an acute medical condition to crop up before diagnosis and treatment in training of medics is fast becoming obsolete. The introduction of simulation into health care curriculum is a reference point because it provides the platform to train, assess and get feedback on the performance of medical personnel. Though a simulated environment is controlled but the opportunity it presents to replicate so many medical cases and how optimal students reacts in such cases shows that it is a technique which can be used to assess students performance rather than waiting for a severe medical condition to occur which may never present itself throughout students stay in medical school.

- Confidence and competence builder - The ability to observe one's individual action in a team through audio visual devices creates an atmosphere for clinicians to build their ego, confidence and competence thus improving their learning experience, since situation can be replicated even when they are rare, all procedures seams real, medics tends to sharpen their skills under less tension.

- Managing disaster - Disaster drills such as earthquake, fire outbreak, nuclear, chemical and biological explosions can only be achieved through simulation. If it were real, the damage may be 
unquantifiable and devastating. Response in form of timing, accuracy, controlling the spread and treatment is a factor and the only avenue to examine the efficiency of medical trainees is only achievable through simulation.

- Team training - Medical simulation is interdisciplinary (it is applicable to all sectors of the health profession) i.e. clinicians, nurses, physiotherapists, medical technicians etc. thus creating an enabling environment to train/retrain a group of intellects to work together as team [15].

\section{SIMULATION TRAINING VERSUS TRADITIONAL MEDICAL TRAINING IN CLINICAL EDUCATION}

\begin{tabular}{|c|c|}
\hline Simulation Training & $\begin{array}{c}\text { Traditional Medical } \\
\text { Training }\end{array}$ \\
\hline $\begin{array}{l}\text { In a patient safe environment, } \\
\text { it encourages training to } \\
\text { competence. }\end{array}$ & $\begin{array}{l}\text { Training is based on } \\
\text { apprenticeship time. }\end{array}$ \\
\hline $\begin{array}{l}\text { Rare clinical scenarios can be } \\
\text { planned and staged for } \\
\text { medical trainees. }\end{array}$ & $\begin{array}{l}\text { Complex clinical situation } \\
\text { may not present itself. }\end{array}$ \\
\hline $\begin{array}{l}\text { Practicing physicians can be } \\
\text { provided with scheduled and } \\
\text { regular medical education in } \\
\text { non-threatening manner. }\end{array}$ & $\begin{array}{l}\text { Practicing physicians gain } \\
\text { experience in medical } \\
\text { education sometimes in a } \\
\text { threatening manner on the } \\
\text { job. }\end{array}$ \\
\hline $\begin{array}{l}\text { Evaluation to get immediate } \\
\text { feedback for reflective } \\
\text { thinking. }\end{array}$ & $\begin{array}{l}\text { The probability of getting } \\
\text { prompt feedback is very low. }\end{array}$ \\
\hline $\begin{array}{l}\text { An insurance claim through } \\
\text { bad malpractice doesn't } \\
\text { exist. }\end{array}$ & $\begin{array}{l}\text { Clinical errors on the part of } \\
\text { medics may cause him to } \\
\text { lose his job, medical } \\
\text { certificate and may even lead } \\
\text { to insurance claims. }\end{array}$ \\
\hline $\begin{array}{l}\text { Students/physicians can learn } \\
\text { from their failure in a } \\
\text { potentially safe environment. }\end{array}$ & $\begin{array}{l}\text { It may involve "live patients" } \\
\text { whose life might be at stake, } \\
\text { therefore it gives no room for } \\
\text { mistakes. }\end{array}$ \\
\hline $\begin{array}{l}\text { Team and multidisciplinary } \\
\text { training is encouraged. }\end{array}$ & $\begin{array}{l}\text { Training is sometimes } \\
\text { individualized. }\end{array}$ \\
\hline Low cost training. & $\begin{array}{l}\text { Cost training may be high } \\
\text { since it may involve use of } \\
\text { expensive patient facilities } \\
\text { such as catheterization } \\
\text { laboratories or operating } \\
\text { rooms. }\end{array}$ \\
\hline $\begin{array}{l}\text { Strikes balance between } \\
\text { patient safety, diagnosis, cure }\end{array}$ & Time management is not \\
\hline
\end{tabular}

\begin{tabular}{|l|l|}
\hline and effective use of time. & adequately catered for. \\
\hline $\begin{array}{l}\text { Consent does not need to be } \\
\text { granted from a "simulated } \\
\text { patient". }\end{array}$ & $\begin{array}{l}\text { Consent of "live patient" is a } \\
\text { key factor. [5] }\end{array}$ \\
\hline
\end{tabular}

\section{HEALTHCARE SERVICES IN AFRICA}

The challenges to better health services in Africa are well known. Africa lacks behind all regions of the world, including other developing regions, on all indicators of better health. A recent report from the World Health Organization for instance shows that while Africa has $20 \%$ of the world's sick people, it has only $4 \%$ of its healthcare workers - many of them vulnerable to the high mortality rate associated with malaria and notably the AIDS epidemic. The state of investment in healthcare infrastructure is also grossly inadequate as is the efficiency of healthcare delivery. Researchers to the volumes of journals have examined the evolution of healthcare services in Africa, the ongoing national, regional and continental efforts to improve the delivery of healthcare in the continent, and the direct and indirect obstacles militating against the maturation of the services and their efficient delivery. All distinguished experts in the field, who hold either challenging responsibilities in health in Africa or have worked in multiple components of the healthcare delivery system in the continent - also provide powerful personal insights and lessons learned in their current or previous work in the health sector in Africa. From their analysis and experience, the authors articulate proven strategies and solutions based on consensus expert opinions on how to improve the quality of health services and health outcomes in Africa [17].

Healthcare demands in Africa are changing. Ensuring access to clean water and sanitation, battling ongoing communicable diseases and stemming the tide of preventable deaths still dominate the healthcare agenda in many countries. However, the incidence of chronic disease is rising fast, creating a new matrix of challenges for Africa's healthcare workers, policy makers and donors [19]. In many parts of Africa, people suffer from a variety of illnesses and diseases that lower their standard of living and set back development. Half of the world's child and maternal deaths occur in Sub-Saharan Africa where, every year, thousands of newborns and mothers die. The majority of these deaths occur within days of childbirth, usually because of a lack of skilled care. More than half of them are preventable. Infection, premature birth, and asphyxia are the biggest newborn killers, with maternal malnutrition an underlying element in 60 to 80 percent of the cases [18]. The causes for these child and maternal deaths include a shortage of health workers, long distances to the nearest health centre, supply shortages and poverty. There is a wide gap in the quality of health care received by people living in cities and those living in rural areas. In short, Africa's current health systems are unable to meet people's needs. Without action to strengthen health systems, many countries of sub-Saharan Africa will not meet the health-related Millennium Development Goals (MDGs) -not because they are unattainable but because current health systems and services in those countries are too weak to reach the beneficiaries and achieve the disease-reduction targets of the MDGs [19].

When the benefit incidence of government health spending in Cote d'Ivoire, Ghana, Guinea, Kenya, Madagascar, South 
Africa, and United Republic of Tanzania was researched upon, public facilities provide more than two-thirds of the medical care in these countries. Private non-profit organizations provide the remaining one-third. In the United Republic of Tanzania, for example, private non-profit hospitals account for about half of all hospitals and about 3\% of all health centres. Private for profit medical care is increasing in most of the countries, but from a low base [18]. In concluding, the health care services in Africa is still dragging and discouraging. The government of the various countries of Africa, particularly in West Africa have made effort, the NGOs and International health organizations have also intervened in the case, yet such efforts were not enough because they have been soiled by the health workers with their lethargic attitude/skills on one part, and on the other part the health care delivery system of many African countries need to be reviewed so that they could be restructured to meet up with the present health needs of their citizenry.

\section{SETBACKS INVOLVED IN USING MEDICAL SIMULATORS}

Machines are not $100 \%$ efficient; error allowances of minute percent must be taken into consideration. On that note as good and flourishing medical simulation is, it has its own setbacks. Medical simulators are non-living objects which can't replicate the process of communication, demonstration of emotions provided by human beings and as such its feedbacks may be close to precision but not perfect. Furthermore since medical simulation focuses solely on training, many authors have argued that it tends to make trainees ignore an essential component of medical practice which is human skill of caring. [6]

\section{CONCLUSION}

It is saddening that in this millennium while the government of developed nations places high premium on lives by investing adequate funds and ensuring that the best staff is allowed to manage their health sector, the continent of Africa is foot dragging. It is either there is shortage of skilled manpower or inadequate funding, while the authors of this paper acknowledges that funding is another important factor to consider in building an effective and efficient healthcare system in Africa. The authors only limited its work to numerous advantages of medical simulation in training, teaching and evaluation of medics in gaining adequate skills needed for a better healthcare system. Medical simulation is fast becoming a "phenomenon" for training; developing nations in Africa can tap into the limitless opportunities and benefits to train residents and retrain practicing medical practitioner in order to achieve a healthcare system that can compete with the developed countries in Europe and America. Perhaps a time will come when delicate and complex surgeries will be performed by African doctors on African soil.

\section{ACKNOWLEDGMENTS}

We sincerely acknowledged the authors of various articles whose work were cited. We are indeed grateful.

\section{REFERENCES}

[1] J. Banks, J. Carson, B. Nelson and D. Nicol, "DiscreteEvent System Simulation" Prentice Hall. pp. 3, (2001) ISBN 0-13- 088702-1

[2] In the words of the Simulation article in Encyclopedia of Computer Science, "designing a model of a real or imagined system and conducting experiments with that model".

[3] J.A Sokolowski and C.M Banks, "Principles of Modeling and Simulation". Hoboken, NJ: Wiley. pp. 6, (2009). ISBN 978-0-470-28943-3.

[4] (2013) The Simulation Wikipedia website [online]. Available: http://en.wikipedia.org/wiki/Simulation.

[5] J.G Murphy, G.C Cremonini and. W. D. Kane, "Is simulation based medicine training the future of clinical medicine", European Review for Medical and Pharmacological Sciences, vol. 11 pp. 1-8, 2007.

[6] Kevin Kunler "The role of medical simulation: an overview" The international journal of medical robotics and computer assisted surgery (2006); vol. 2 pp. 203210.TheWileywebsite[online].Available:http://www.inter science.wiley.com/.

[7] K. Ahmed, AN.Keeling, M.Fakhry, H. Ashrafian, R. Aggarwal, P.A. Naughton, A. Darzi, N.Cheshire, et al. "Role of Virtual Reality Simulation in Teaching and Assessing Technical Skills in Endovascular Intervention". J Vasc Interv Radiol 21. January 2010.

[8] N. Roger, K. Prashant, S.feir. C. Lee. D.H. Choi. Daiwon and Olton, Dana "Nanostructured ceramics in medical devices: Applications and prospects". JOM 56 (10): pp. 38-43. October 2004.

[9] P. Couvreur and C. Vauthier. "Nanotechnology: intelligent design to treat complex disease". Pharm. Res. 23 (7): 1417-50. July 2006.

[10] S.Hede and N. Huilgol, "Nano": the new nemesis of cancer". J Cancer Res Ther 2 (4): 186-95, 2006.

[11] S.P. Leary, C.Y. Liu and M.L.Apuzzo "Toward the emergence of nanoneurosurgery: part IIInanomedicine: targeted nanotherapy, nanosurgery, and progress toward the realization of nanoneurosurgery". Neurosurgery 58 (6): 1009-26; June 2006

[12] J.B. Cooper and V.R. Taqueti "A brief history of the development of mannequin simulators for clinical education and training”, Qual Saf Health Care; 13:11-8, 2004.

[13] K. R. Rosen MD. "The history of medical simulation", Journal of Critical Care, vol. 23, pp. 157-166, 2008.

[14] G.H. Buck, "Development of simulators in medical education", Gesnerus, 48, pp. 7, 1991.

[15] J. Barjis, "Healthcare Simulation and its Potential Areas and Future Trends".SCM, M\&S Magazine-January, 2011.

[16] D.M Gaba "The future vision of simulation in health care". Quality and Safety in Health Care, vol. 13, i2-i10, 2004.

[17] A. Chinua, "Healthcare Services in Africa: Overcoming Challenges, Improving Outcomes", Adonis and Abbey Publisher Ltd. 2006.

[18] CIDA, The Africa Health Systems Initiative (AHSI), Canadian International Development Agency (CIDA), 2012.

[19] Economics Intelligence Unit, "The future of healthcare in Africa”, 2012. 